\title{
Experimental Pseudomonas keratitis in guinea-pigs: therapy of moderately severe infections
}

\author{
STARKEY D. DAVIS, LARRRIE D. SARFF, AND ROBERT A. HYNDIUK \\ From the Departments of Pediatrics and Ophthalmology, Medical College of Wisconsin, \\ Milwaukee Children's Hospital, and the Cornea-External Disease Unit, The Eye Institute, \\ Milwaukee, Wisconsin, USA
}

SUMMARY We have previously shown that antibiotic therapy of experimental Pseudomonas keratitis was more effective in early moderate infections than in late severe infections. The purpose of this study was to determine the relative efficacies of various drugs, routes, and vehicles in the treatment of moderately severe infection. As in the late severe infections, the most consistently effective regimen was an aminoglycoside applied topically in solution. No synergistic or additive effect was observed with a combination of aminoglycoside given topically and a penicillin given intramuscularly. Topical therapy with antibiotic in ointment was less effective than topical therapy with antibiotic in solution.

We have developed a reproducible, quantitative model of experimental Pseudomonas keratitis in guinea-pigs. Animals are infected by intracorneal injection to ensure that all corneas receive the same inoculum. Within 24 hours all infected corneas show frank keratitis. Results of treatment are assessed objectively by determining the number of bacteria surviving in the cornea (Davis and Chandler, 1975; Davis et al., 1977; Davis et al., 1978).

Efficacy of treatment of experimental Pseudomonas keratitis in guinea-pigs was enhanced by beginning therapy sooner after infection rather than later when a more severe infection was present. Earlier therapy was presumably more effective in part because there were fewer bacteria in the cornea (Davis et al., 1978).

At 16 hours after infection in this model the number of viable bacteria in the cornea has increased from a geometric mean of 10 to a geometric mean of 48000 . An abscess is beginning to form in the cornea. After 24 hours a geometric mean of 280000 organisms are present and abscess formation is more advanced (unpublished observations). We believe that a patient with a corneal infection may well first seek medical attention at the 16-hour stage.

Address for reprints: Dr Starkey D. Davis, MD, Department of Pediatrics, Milwaukee Children's Hospital, 1700 West Wisconsin Avenue, Milwaukee, Wisconsin 53233, USA
Here we present results of trials in which antibiotic therapy was begun 16 hours after infection. Our purpose was to determine whether the relative efficacy of antibiotics would change when infection was less severe.

\section{Materials and methods}

These have been previously reported in detail (Davis and Chandler, 1975; Davis et al., 1977; Davis et al., 1978). Briefly, male Hartley strain guinea-pigs weighing 300 to $350 \mathrm{~g}$ were infected intracorneally with about 10 viable Pseudomonas aeruginosa strain 107,110 , or 113. Antibiotic therapy was begun 16 hours later. At the end of the experiments the animals were killed and the corneas were excised and ground in broth. Numbers of viable bacteria were determined by quantititative subcultures. The results were analysed statistically by analysis of variance (Snedecor and Cochran, 1967). Data are presented as means and standard deviations of the numbers of viable bacteria in common logarithms (base 10). The mean of numbers expressed in common logarithms is equivalent to the geometric mean. Analysis of data in this way dampens the effect of single extreme values.

Antibiotics were obtained through the hospital pharmacy or directly from the pharmaceutical company. Parenteral formulations of aminoglycosides were diluted in sterile $0.15 \mathrm{M} \mathrm{NaCl}$ for 
Table 1 Therapy of moderately severe experimental Pseudomonas keratitis in guinea-pigs*

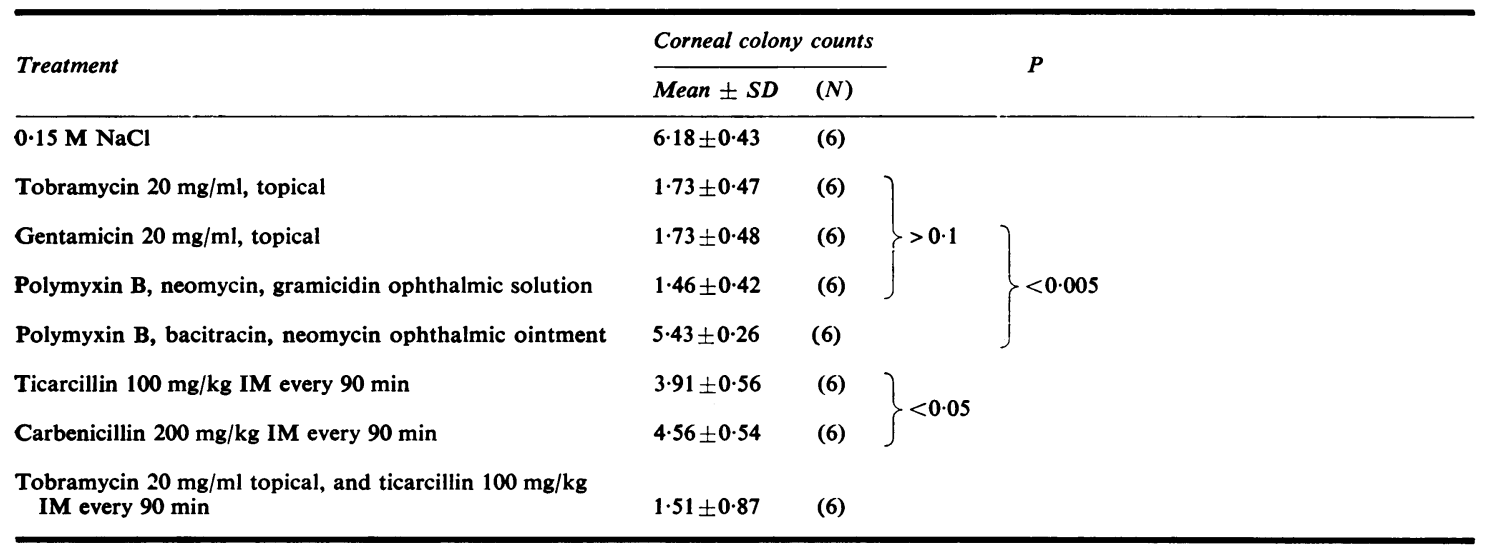

*Animals were infected intracorneally and treatment was begun 16 hours later. Topical treatment was given as 2 drops every 30 minutes. Ointment was applied every 2 hours. Treatment was given for 16 hours, and then all animals were killed.

Table 2 Therapy of moderately severe experimental Pseudomonas keratitis*

\begin{tabular}{|c|c|c|c|}
\hline \multirow{2}{*}{ Treatment } & \multicolumn{2}{|c|}{ Corneal colony counts } & \multirow{2}{*}{$P$} \\
\hline & $M e a n \pm S D$ & $(N)$ & \\
\hline $0 \cdot 15 \mathrm{M} \mathrm{NaCl}$ & $6.07 \pm 0.89$ & (6) & \\
\hline Tobramycin $20 \mathrm{mg} / \mathrm{ml}$, topical & $0.70 \pm 0.78$ & (6) & \\
\hline Gentamicin $20 \mathrm{mg} / \mathrm{ml}$, topical & $0 \cdot 17 \pm 0 \cdot 41$ & (6) & \\
\hline Amikacin $20 \mathrm{mg} / \mathrm{ml}$, topical & $0.79 \pm 0.88$ & (6) & \\
\hline $\begin{array}{l}\text { Polymyxin B, neomycin, gramicidin ophthalmic solution, } \\
\text { topical }\end{array}$ & $1 \cdot 19 \pm 1.99$ & (6) & $<0.005$ \\
\hline $\begin{array}{l}\text { Polymyxin B, bacitracin, and neomycin ophthalmic } \\
\text { ointment, topical }\end{array}$ & $4 \cdot 06 \pm 1 \cdot 50$ & (6) & \\
\hline Ticarcillin $100 \mathrm{mg} / \mathrm{kg} \mathrm{IM}$ & $1.85 \pm 1.33$ & (6) & \\
\hline $\begin{array}{l}\text { Ticarcillin } 100 \mathrm{mg} / \mathrm{kg} \mathrm{IM,} \mathrm{and} \mathrm{tobramycin} 20 \mathrm{mg} / \mathrm{ml} \text {, } \\
\text { topical }\end{array}$ & $0.33 \pm 0.52$ & (6) & \\
\hline
\end{tabular}

- Therapy was begun 16 hours after infection and was given continuously for 24 hours. Topical solutions were given 2 drops every 30 minutes. Ointment was applied topically every 2 hours. Ticarcillin was given IM every 90 minutes.

topical use. An ophthalmic solution of polymyxin B 5000 units $/ \mathrm{ml}$, neomycin $1.75 \mathrm{mg} / \mathrm{ml}$, and gramicidin $0.025 \mathrm{mg} / \mathrm{ml}$ (Neosporin), and an ophthalmic ointment of polymyxin B 5000 units/g, bacitracin 400 units $/ \mathrm{g}$, and neomycin $3.5 \mathrm{mg} / \mathrm{g}$ (Neosporin) were used topically as formulated.

The strains of Pseudomonas were susceptible to the antibiotics used by standard in-vitro tests (Davis et al., 1977).

\section{Results}

For the trial presented in Table 1 animals were infected intracorneally, and treatment was begun
16 hours later. Topical therapy with antibiotics was more effective than therapy with saline $(\mathrm{P}<0.005)$. Tobramycin $20 \mathrm{mg} / \mathrm{ml}$, gentamicin $20 \mathrm{mg} / \mathrm{ml}$, and a topical solution of polymyxin $B$, neomycin, and gramicidin were equally effective. Ointment containing the polymyxin B, bacitracin, and neomycin was significantly less effective than the topical solutions. Parenteral therapy with ticarcillin and carbenicillin was more effective than saline but less effective than topical therapy with antibiotic solutions $(P<0.005)$. Parenteral therapy with ticarcillin did not enhance the efficacy of topical therapy with tobramycin $20 \mathrm{mg} / \mathrm{ml}(\mathrm{P}>0 \cdot 1)$.

In the trial shown in Table 2 therapy was begun 
Table 3 Topical therapy trials of moderately severe experimental keratitis in guinea-pigs infected with 3 strains of Pseudomonas aeruginosa*

\begin{tabular}{|c|c|c|c|c|}
\hline \multirow{2}{*}{ Pseudomonas strain } & \multirow{2}{*}{ Treatment } & \multicolumn{2}{|c|}{ Corneal colony counts } & \multirow{2}{*}{$\boldsymbol{P}$} \\
\hline & & Mean $\pm S D$ & $(N)$ & \\
\hline \multirow[t]{3}{*}{107} & $0 \cdot 15 \mathrm{M} \mathrm{NaCl}$ & $6 \cdot 21 \pm 0 \cdot 17$ & (6) & \multirow{3}{*}{$<0.005$} \\
\hline & Tobramycin $20 \mathrm{mg} / \mathrm{ml}$ & $1 \cdot 38 \pm 0 \cdot 74$ & (6) & \\
\hline & Polymyxin B, neomycin and gramicidin & $5.00 \pm 0.63$ & (6) & \\
\hline \multirow[t]{3}{*}{110} & $0 \cdot 15 \mathrm{M} \mathrm{NaCl}$ & $4 \cdot 55 \pm 1 \cdot 82$ & (4) & \multirow{3}{*}{$<0.005$} \\
\hline & Tobramycin $20 \mathrm{mg} / \mathrm{ml}$ & $1.06 \pm 0.64$ & (5) & \\
\hline & Polymyxin B, neomycin, and gramicidin & $1 \cdot 87 \pm 2 \cdot 56$ & (5) & \\
\hline \multirow[t]{3}{*}{113} & $0 \cdot 15 \mathrm{M} \mathrm{NaCl}$ & $4 \cdot 73 \pm 1 \cdot 00$ & (6) & \multirow{3}{*}{$<0.005$} \\
\hline & Tobramycin $20 \mathrm{mg} / \mathrm{ml}$ & $1.62 \pm 0.94$ & (6) & \\
\hline & Polymyxin B, neomycin and gramicidin & $2 \cdot 95 \pm 0 \cdot 87$ & (6) & \\
\hline
\end{tabular}

*Topical therapy of 2 drops every 30 minutes was begun 16 hours after infection and was given for 48 hours.

16 hours after infection and was continued for 24 hours. All antibiotic therapies were more effective than saline $(P<0.005)$. Topical therapy with solutions of tobramycin, gentamicin, amikacin, and a solution of polymyxin B, neomycin, and gramicidin were equally effective. The ointment containing polymyxin $\mathrm{B}$, bacitracin, and neomycin was significantly less effective than the solutions $(P<0 \cdot 005)$. Ticarcillin by intramuscular injection did not improve the efficacy of topical therapy with tobramycin in solution $(\mathrm{P}>0.1)$.

Table 3 presents results of trials on 3 strains of Pseudomonas with tobramycin $20 \mathrm{mg} / \mathrm{ml}$ and a solution of polymyxin B, neomycin, and gramicidin. Tobramycin was significantly better than saline with all 3 strains. The solution of polymyxin B, neomycin, and gramicidin was not more effective than saline with strain 107 . Tobramycin was more effective than the solution of polymyxin $B$, neomycin, and gramicidin with strain $107(\mathrm{P}<0.005)$ but not with strain $110(P>0 \cdot 1)$ or strain $113(P>0.05)$.

\section{Discussion}

In experimental keratitis in guinea-pigs antibiotic therapy was more efficacious when begun earlier than when begun later when the lesion was more severe (Davis et al., 1978). Thus, therapy trials begun at 24 hours after infection constitute a more rigorous test of antibiotic therapy than trials begun at 16 hours after infection (Davis et al., 1977). Trials begun at 16 hours after infection may possibly have greater clinical relevance than trials begun later, because an early abscess is beginning to form. Intuitively it seemed possible that some agents might be more effective in moderately severe lesions and less effective for the later, more severe lesions. The results presented show that this is not so.

Considering the data shown here and our previous work, we conclude that the most consistently effective therapy of experimental Pseudomonas keratitis in the guinea-pig is an aminoglycoside antibiotic given topically in solution. The combination of polymyxin B, neomycin, and gramicidin was significantly less effective in several trials (Davis et al., 1977). We concluded previously that polymyxin B alone in solution was significantly less effective than gentamicin or tobramycin in solution (Davis et al., 1977). The ointment containing polymyxin $\mathrm{B}$, bacitracin, and neomycin was inferior in efficacy to solutions of antibiotic. Intramuscular therapy with penicillins was less effective than topical therapy with aminoglycoside solutions in concentrations greater than $3 \mathrm{mg} / \mathrm{ml}$. Intramuscular therapy with carbenicillin or ticarcillin did not significantly improve results of topical therapy with an aminoglycoside. In 1 trial, tobramycin, gentamicin, and amikacin were equally effective when applied topically in equal concentrations.

In brief, the most consistently effective therapy for experimental Pseudomonas keratitis in guineapigs is a topical aminoglycoside solution in the highest concentration that can be applied with safety (Davis et al., 1977; Davis et al., 1978). The relative efficacy of antimicrobial agents in this model did not change regardless of whether the therapy was started 16 or 24 hours after infection.

This work is supported in part by NIH Grant EY01665, by Eye Center Grant I-P30-EY01931, by Eli Lilly \& Co., Indianapolis, Indiana, by Bristol Laboratories, Syracuse, 
New York, by Beecham Laboratories, Bristol, Tennessee, and by Research to Prevent Blindness.

Germaine Pautzke gave expert technical assistance, and L.D.S. did the statistical analysis.

\section{References}

Davis, S. D., and Chandler, J. W. (1975). Experimental keratitis due to Pseudomonas aeruginosa. Antimicrobial Agents and Chemotherapy, 8, 350-355.
Davis, S. D., Sarff, L. D., and Hyndiuk, R. A. (1977). Antibiotic therapy of experimental Pseudomonas keratitis in guinea pigs. Archives of Ophthalmology, 95, 16381643.

Davis, S. D., Sarff, L. D., and Hyndiuk, R. A. (1978). Topical tobramycin therapy of experimental Pseudomonas keratitis: an evaluation of some factors which potentially enhance efficacy. Archives of Ophthalmology, 96, 123-125.

Snedecor, G. W., and Cochran, W. G. (1967). Statistical Methods, 6th ed., pp. 258-298. Iowa State University Press: Ames, Iowa. 